Please send trade news information and illustrations to Terry Mordecai at the BDJ, 64 Wimpole Street, London W1G 8YS.

Trade news is supplied as a service to the reader and does not imply endorsement by the BDJ. Normal and prudent research should be exercised before purchase or use of any product mentioned.

\section{A new generation of surgeries}

Harley Street is to see the launch of a new dental clinic and centre for facial rejuvenation that will host the services of some of the top specialists as part of a 37 strong dentist team.

The clinic spread over 5 floors consists of several surgeries, waiting rooms, recovery rooms and spas using leading edge technology. At 139 Harley Street the clinic also boasts seminar and training facilities that have already been booked by several dental product suppliers and senior lectures for courses and product launches.

To find out more visit www.qclinic.com

Reader response number 52

\section{A free CiC V8 Explorer}

MEDiVision is pleased to announce that surgeries can now receive the $\mathrm{CiC}$ V8 Explorer on trial for free. MediVision claims a fully functional version of CiC V8 Explorer enables dentists to 'try before you buy'.

The trial CD affords an insight into the quality and flexibility of CIC V8 Explorer and includes 3 full animations, 11 thumbnail animations, 3 complete patient leaflets, and 100 clipart images.

For full details call MEDiVision on 01908 $265565 . \quad$ Reader response number 53

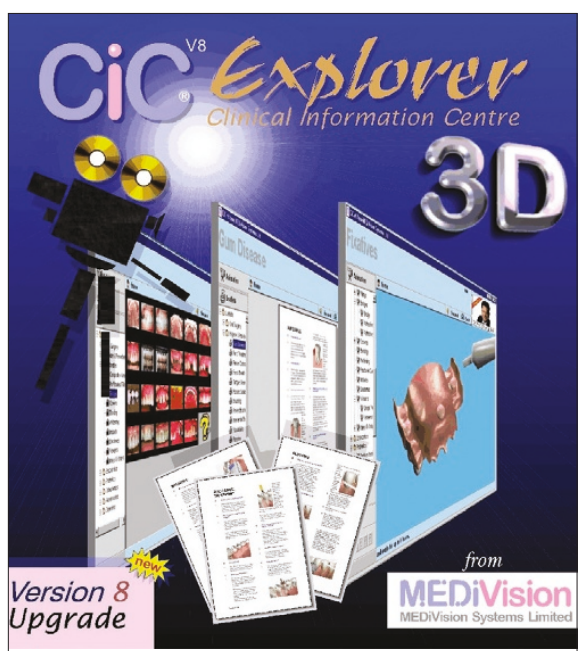

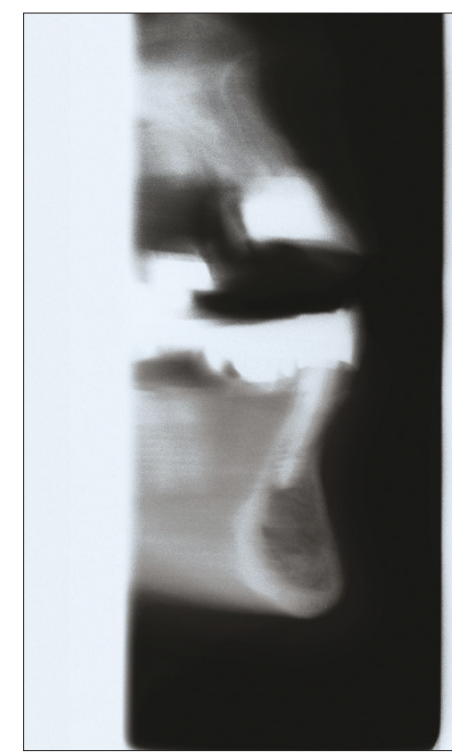
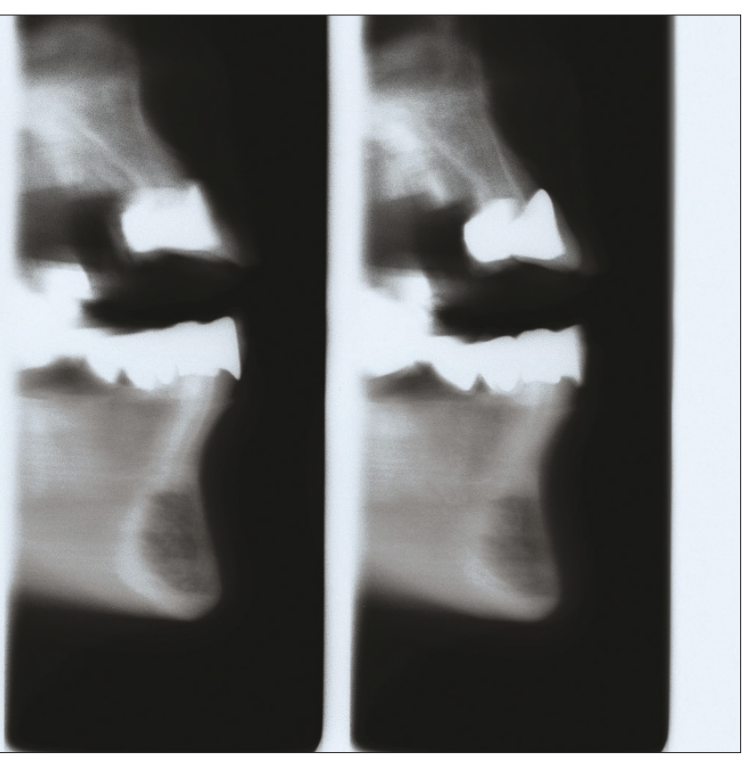

\section{Get the Orthoralix for your surgery}

Dentsply is pleased to announce the launch of the new Orthoralix 9200 PLUS panoramic X-ray unit. Dentsply claims the Orthoralix 9200 offers specialised programmes for DentoMaxillo-Facial (DMF) radiology in addition to standard projections.

Dentsply claims the unit has been designed to suit the radiographic requirements of all dental professionals, including GDPs and maxillo-facial surgeons. Dentsply also claims the cephalometric option will appeal to orthodontists, whilst implantologists will appreciate the diagnostic capabilities of the DMF and Transcan (linear tomography) projections. For more information or a demonstration contact Roxane Bellière at Dentsply on 01932 853422 or via e-mail on roxane.belliere@dentsply-gb.com.

Reader response number 51

\section{Microflex gloves are now available here}

Microflex gloves are now available to UK dentists through Ferno. The Microflex gloves are renowned in the US and are used in a wide range of areas including the emergency services, laboratory and dental industries.

Included in the range is the Diamond Grip Plus which is a powder-free, low-odour latex glove offering outstanding sensitivity and sure wet/dry gripping properties and is designed specifically for dental use

Microflex offer a wide range of gloves in latex and synthetic materials including nitrile and chloroprene. Microflex promises the lowest failure rates, the lowest residual chemical ratings and the lowest protein levels in the glove industry. For free sample packs, information or sales on the range of Microflex gloves phone Ferno UK 1274851 999.

Reader response number 54

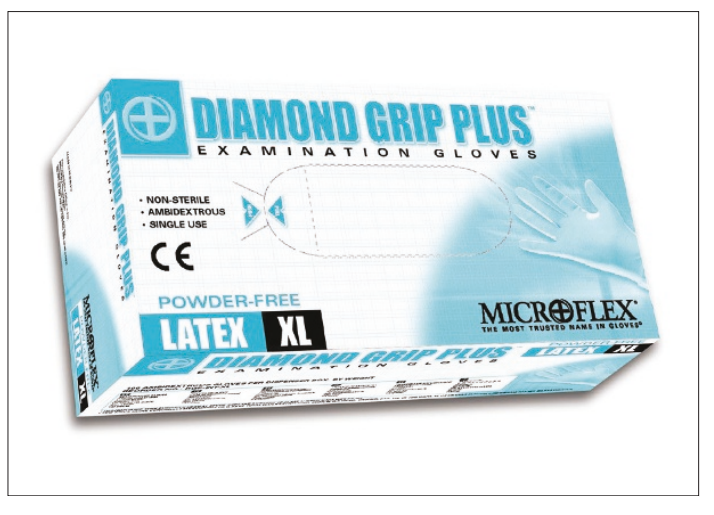

